\title{
Poly(methylhydrosiloxane)-supported chiral thiourea-based bifunctional catalysts
}

\begin{abstract}
The design, the synthesis and the successful immobilization of a modified Takemoto's catalyst is described. As support, poly(methylhydrosiloxane (PMHS) was chosen for its several positive features: it is a cheap, commercially available polymer, easily functionalized with simple experimental procedures. The PMHS-anchored enantiomerically pure bifunctional organocatalyst was employed in the stereoselective addition of activated carbon nucleophiles to nitrostyrene and its recovery and recyclability was preliminarily investigated.
\end{abstract}

\section{Keywords}

Organocatalysis • Supported catalysts $\bullet$ Poly(methylhydrosiloxane) $\bullet$ Chiral thioureas - Michael addition

(C) Versita Sp. z o.o.

\begin{tabular}{ll}
$\begin{array}{l}\text { Alessandra Puglisi', } \\
\text { Maurizio Benaglia'*, }\end{array}$ & $\begin{array}{l}\text { Elisabetta Massolo', } \\
\text { Giuseppe Celentano }\end{array}$ \\
\hline 'Dipartimento di Chimica, & 'Dipartimento di Scienze Farmaceutiche, \\
$\begin{array}{l}\text { Universita' degli Studi di Milano, } \\
\text { via Golgi 19, 20133, Milano, Italy }\end{array}$ & Università degli Studi di Milano, \\
& Via Mangiagalli 25, 20133, Milano, Italy
\end{tabular}

Received 11 June 2012

Accepted 16 July 2012
The immobilization of a chiral catalyst on a polymer support offers a clear advantages in recovering of the precious catalytic species [1], streamlining the reaction work up and facilitating the isolation of the product. The development of a supported catalyst allows not only an easy recovery but also the recycle of the possibly expensive chiral promoter. Finally, anchoring a catalytic species may also address environmental issues and enable better studies of catalyst structure, stability and overall performance (both selectivity and activity) [2]. In all of these contexts, the choice of the support and in particular of its solubility properties is crucial. Among a variety of available soluble supports, polymethylhydrosiloxane (PMHS) presents many positive features: it is a commercially available, inexpensive polymer that can be readily functionalized [3]. Also its solubility properties can be properly tuned by a judicious choice of the organic residues to be attached to the polymeric backbone [4].

In the area of "Organocatalysis", these tailored macromolecules maintain low equivalent weight and good solubility characteristic of lower molecular weight "homogenous" embodiments while providing easy catalyst confinement and recovery methods, which address separation, recycling, and waste management issues [5]. Despite the ready availability and attractive chemical characteristics of PMHS, its use as catalyst support is relatively underdeveloped; after pioneering work with PMHS supported cinchona alkaloid derivatives, employed by Siegel as recyclable ligands for the Sharpless dihydroxylation reaction [6], it was only recently that our group started to investigate the development of PMHS-immobilized chiral organic catalysts. Supported MacMillan's imidazolidin-4-ones were shown to mediate very efficiently the stereoselective DielsAlder cycloaddition of dienes with a,b-unsaturated aldehydes; the reaction occurred in yields and enantiomeric excesses comparable to those observed with the non-supported catalysts (up to $93 \%$ e.e.). Remarkably, the reaction could be carried out also in pure water and for least five reaction cycles with a recovered catalyst [7].

More recently we reported the preparation and the application of two PMHS-supported enantiomerically pure bifunctional organocatalysts in organocatalytic stereoselective transformations; a supported Takemoto type catalyst promoted the diethyl malonate addition to nitrostyrene in fair to good yields and up to $83 \%$ e.e.; modest recyclability was demonstrated.

However, performances and recyclability of the supported Takemoto-like catalyst were not completely satisfactory; we wish to report herein further studies related to a new approach for connecting a chiral thiourea-based bifunctional catalyst to the polymer. Diethyl malonate addition to nitrostyrene was employed as model reaction to test the chemical and stereochemical activity of the novel supported chiral organocatalysts and their recoverability and recyclability was also preliminarily investigated.

Until this year only one example of supported Takemoto's catalyst A [9], a poly(ethylene glycol)-anchored catalyst of type $B$, was known and it was reported to be able to promote the diethylmalonate addition to nitrostyrene in decent yields $(67 \%)$ and e.e. (87\%), The long reaction times, however, required for the reaction ( $144 \mathrm{~h}$ ) and the low loading of the supported catalyst $(0.18 \mathrm{meq} / \mathrm{g}$ of polymer) left much space for further improvement and optimization. Therefore, investigation of Takemoto's catalyst supported on a different soluble polymer like PMHS attracted our attention. Supported catalyst of type B was prepared and it was used in the Michael addition of diethyl malonate to nitro styrene in DCM, affording the product in $53 \%$ yield and $80 \%$ e.e. The reaction in toluene led to worse results; working at lower 
<smiles>CN(C)C1CCCCC1NC(=S)Nc1cc(C(=O)Nc2ccccc2)cc(C(=O)OCc2cn(C3CCCCC3)nn2)c1</smiles>

Takemoto's catalyst

Novel supported Takemoto's catalyst

A

Chart 1. Chiral thio-urea based amino catalysts.<smiles>O=C(O)c1cc([N+](=O)[O-])cc(C(F)(F)F)c1</smiles>

1
$\mathrm{F}_{3} \mathrm{C}$

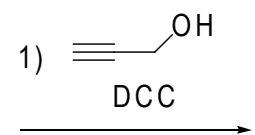

2) $\mathrm{SnCl}_{2}$<smiles>C#CCOC(=O)c1cc(N)cc(C(F)(F)F)c1</smiles>

2

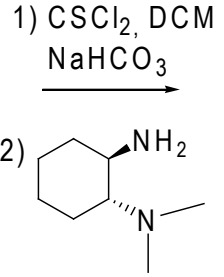

$\mathrm{CSCl}_{2}, \mathrm{DCM}$<smiles>C#CCOC(=O)c1cc(NC(=S)N[C@H]2CCCCC2N(C)C)cc(C(F)(F)F)c1</smiles>

3

Scheme 1. Synthesis of modified chiral thiourea 3.

temperature the product was obtained with a marginal increase in enantioselectivity, but with a clear drop in chemical yield. Also the recycling of the recovered catalyst was attempted; the high level of enantioselectivity was maintained in the first two cycles (77-79\% e.e.) but a constant decrease of the chemical efficiency was observed [8].

In the attempt to improve the chemical and stereochemical performances of the chiral catalyst, we decided to explore a new approach to immobilize a properly modified chiral organocatalyst to PMHS through click chemistry, the copper catalyzed cycloaddition between an alkyne and an azido group. Based on the previous reports $[7,8]$ one of the trifluoromethyl groups of A was replaced with another electron-withdrawing group, like a carboxylic acid, that provided the handle for the attachment of the chiral organic residue to the polymer in a relatively remote region of the catalyst's structure. The synthetic strategy employed in the preparation of the properly modified organocatalyst is depicted in Scheme 1. Starting from 3-nitro5-trifluoromethyl benzoic acid 1, the corresponding propargyl ester 2 was prepared in two steps and $90 \%$ overall yield. The conversion of amine group into the corresponding isothiocyanate followed by condensation with $(R, R)-1-N, N$-dimethylamino-2aminocyclohexane [10] afforded the chiral thiourea bifunctional catalyst 3 in $65 \%$ yield.

Then a polymer bearing the azido group was prepared; two types of functional materials were synthesized: in one case the O-allyl ether of 4-hydroxy benzyl alcohol was connected through platinum catalyzed hydrosilylation to PMHS to afford monofunctionalized polymer 4; analogously the same allyl aryl ether was successfully connected to poly(methylhydrosiloxane) in the presence of variable amounts of phenyl allyl ether 5 in order to prepare materials that differed for the loading and the spatial orientation of the chiral organic residue on the polymer chain; only the bifunctional polymer 5 with $x / y$ ratio of $1: 1$ is shown in Scheme 2.

Polymers 4 and 5 were then converted in the corresponding azido derivatives 6 and 7 via conversion of hydroxyl group into bromide followed by reaction with sodium azide in THF. Finally, the copper catalyzed cycloaddition allowed the attachment of the chiral bifunctional catalyst 3 to the properly functionalized polymers to afford the PMHS-supported Takemoto's catalyst 8 and 9. It is worth mentioning that by this approach a thiourea-based catalyst was synthesized, while in the previous methodology only the urea derivative had been obtained.

Finally, the catalytic behaviour of the supported catalysts 8 and 9 was investigated in the model reaction of diethyl malonate addition to nitrostyrene in different conditions (Scheme 3; Table 1); for sake of comparison the performance of the modified Takemoto-like catalyst 3 is also reported [11].

First the performance of 3 , a Takemoto-like modified catalyst was compared with those of Takemoto's catalyst (entry 3 vs entries 1-2, Table 1). With respect to catalyst type A, the propargyl derivatives 3 behaved well and promoted the reaction in comparable yields and only a little lower 


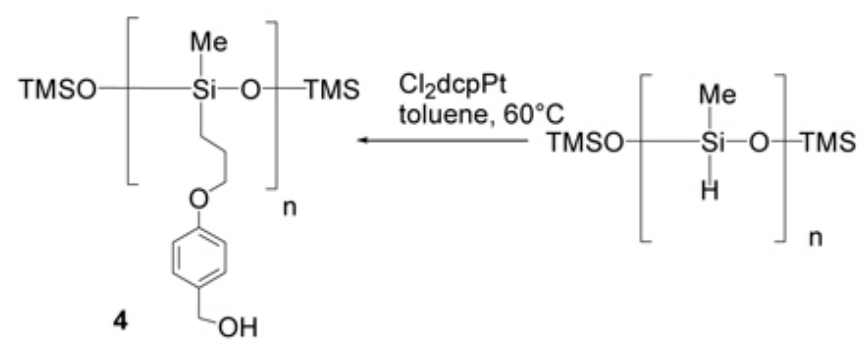

1<smiles>CO[Si](C)(C)C(C)(C)[Si](C)(CCCOc1ccc(CN)cc1)OC(C)(C)C</smiles>

6

3 CuCl cat.<smiles>CCC(C)(CC(C)(OC)O[Si](C)(CCCOc1ccc(Cn2cc(COC(=O)c3cc(NC(=O)N[C@@H]4CCCCC4N(C)C)cc(C(F)(F)F)c3)nn2)cc1)OC)O[Si](C)(C)C</smiles>
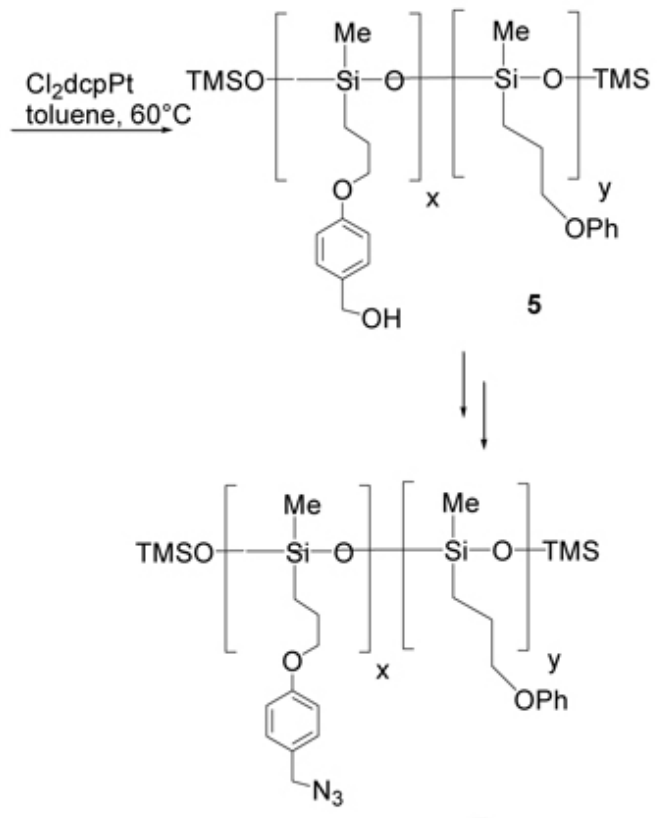

7

$3 \mathrm{CuCl}$ cat.

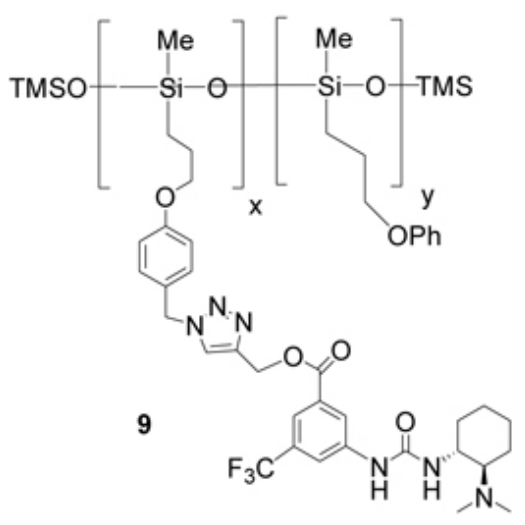

Scheme 2. Synthesis of supported chiral catalysts 8 and 9 .

enantioselectivity. Then supported catalysts 8 and 9 were tested in the same experimental conditions; monofunctional polymer-supported organocatalysts 8 showed clearly to be a worse promoter of the reaction, both chemically and stereochemically (entries 4-5) compared to species 9. Presumably a catalytic site isolation is required to allow to the chiral catalytically active bifunctional system (thioureatertiary amine) to work properly; indeed polymer 9 where the organocatalytic units are kept more separated by the insertion on the polymer chain of the phenyl-allyl ether inter residue afforded better results. It was able to promote the reaction in $47 \%$ yield and $77 \%$ e.e. in toluene, while in DCM higher yields but lower enantioselectivity were observed (entries $6-7$, Table 1). Working at lower temperature the product was obtained with a marginal increase in enantioselectivity, but with a clear drop in chemical yield.

The catalytic activity of catalyst 9 was evaluated also in the model reaction between trans $\beta$-nitrostyrene and acetyl acetone; the reaction was performed in the presence of $10 \mathrm{~mol} \%$ of catalyst for 24 hours in $\mathrm{DCM}$ at $25^{\circ} \mathrm{C}$. The product was obtained in $30 \%$ yield and $51 \%$ e.e.

Finally, recycling of the recovered catalyst was attempted: at the end of reaction, the organic solvent was evaporated under vacuum; the residue was dissolved in the minimum amount of $\mathrm{CH}_{2} \mathrm{Cl}_{2}$ and then poured in hexanes $(10 \mathrm{~mL})$. The precipitate was collected by centrifuge and decanted. The precipitated polymer residue was dissolved in a minimal amount of DCM needed to completely dissolve the crude polymer. From the DCM solution, 
<smiles>O=[N+]([O-])/C=C/c1ccccc1</smiles><smiles>CCOCC(c1ccccc1)C(C[N+](=O)[O-])C(=O)OCC</smiles>

Scheme 3. Organocatalytic addition of diethyl malonate to nitrostyrene.

Table 1. Organocatalyzed addition of diethyl malonate to nitrostyrene.

\begin{tabular}{|c|c|c|c|c|c|}
\hline entry & Solvent & Time $(\mathrm{h})$ & cat & Yield (\%)a & e.eb (\%) \\
\hline \hline $1 c$ & Toluene & 24 & A & 87 & 93 \\
\hline $2 c$ & DCM & 24 & A & 53 & 90 \\
\hline 3 & Toluene & 24 & 3 & 85 & 89 \\
\hline 4 & DCM & 48 & 8 & 27 & 37 \\
\hline 5 & toluene & 48 & 8 & 21 & 25 \\
\hline 6 & toluene & 48 & 9 & 47 & 77 \\
\hline 7 & DCM & 48 & 9 & 61 & 57 \\
\hline $8 d$ & DCM & 48 & 9 & 41 & 77 \\
\hline $9 e$ & DCM & 48 & 9 & 23 & 75 \\
\hline
\end{tabular}

${ }^{a}$ Reactions were run at RT with 3 mol equiv. of diethyl malonate, 1 mol equiv of nitrostyrene and 0.1 mol equiv of catalyst; yields were determined after chromatographic purification; ${ }^{b}$ e.e. was determined by HPLC on chiral column (see supporting Information);

clit. data; ref.8

a recovered catalyst was used.ea second recycled was performed with the recovered catalyst.

the polymer was precipitated again pouring the solution into an excess of hexanes. The average recovery of catalyst ranged from $80 \%$ to $90 \%$ (after drying under high vacuum). The recovered polymer supported catalyst was checked by NMR and reused without further purification. The high level of enantioselectivity was maintained for two cycles (entries 8-9, Table 1) but in the second cycle a clear drop in chemical activity was observed; the degradation of the material was testified also by the difficulty and in the low yield in recovering the polymer-supported catalyst, due to extensive decomposition specially of the polymeric chains.

In conclusion, enantiomerically pure bifunctional catalysts have been immobilized on poly(methylhydrosiloxane). A supported Takemoto type catalyst promoted the diethyl malonate addition to nitrostyrene in fair to good yields and up to $77 \%$ e.e.; this novel supported catalysts promoted the reactions in slightly lower chemical and stereochenical yields compared to the previously reported PMHS-anchored Takemoto type catalyst; modest recyclability was also demonstrated. Although

\section{References}

[1] Review: A. F. Trindade, C.A.M. Afonso, Chem. Rev. 2009, 109, 3401-3429.

[2] a) M. Benaglia, Ed. Recoverable and Recyclable Catalysts 2009, John Wiley and Sons; b) N. Haraguchi, S. Itsuno, different issues need to be addressed (stability of the polymeranchored catalyst, chemical efficiency of the catalyst, easy recovery of the immobilized catalyst) the use of poly(methylhydrosiloxane) as support for the development of recyclable organic catalysts opens interesting perspectives and it is subject of active investigation in our group.

\section{Supporting Information}

${ }^{1} \mathrm{H}-\mathrm{NMR}$ spectra of selected intermediates and of polymer supported catalysts. Experimental details of the stereoselective organocatalytic reactions.

\section{Acknowledgements}

Financial support by MIUR-PRIN (Rome) within the national project "Nuovi metodi catalitici stereoselettivi e sintesi stereoselettiva di molecole funzionali" is gratefully acknowledged. M.B. thanks the European COST Action CM0905-Organocatalysis.
Polymeric Chiral Catalyst Design and Chiral Polymer Synthesis 2011, John Wiley \& Sons.

[3] For a review on PMHS see: N.J. Lawrence, M.D. Drew, S.M. Bushell, J. Chem. Soc. Perkin Trans 1 1999, 3381-3391. For 
recent contributions see J. Gajewy, J. Gawronski, M. Kwit, Org. Biomol. Chem. 2011, 9, 3863-3870 and references cited.

[4] M. S. Bratcher, M. S. DeClue, A. Grunnet-Jepsen, D. Wright, B. R. Smith, W. E. Moerner, J. S. Siegel, J. Am. Chem. Soc. 1998, 120, 9680-9681.

[5] M. Benaglia, A. Puglisi, F. Cozzi, Chem. Rev. 2003, 103, 3401-3429. See also F. Cozzi, Adv. Synth. Catal. 2006, 348, 1367-1390.

[6] M. S. DeClue,, J. S. Siegel, Org. Biomol. Chem. 2004, 2, 2287-2298.
[7] S. Guizzetti, M. Benaglia,, J. S. Siegel, Chem. Comm. 2012, 3188-3190.

[8] A. Puglisi, M. Benaglia, R. Annunziata, J. S. Siegel, Chem. Cat. Chem. 2012, 4, 972-975.

[9] Y. Takemoto, Org. Biomol. Chem. 2005, 3, 4299-4321.

[10] M. Kaik, J. Gawronski, Tetrahedron Asymmetry 2003, 14, 1559-1563.

[11] Typically supported catalyst 9 with a $1: 1 \mathrm{x} / \mathrm{y}$ ratio was employed in catalytic experiments; the use of polymers with different $x / y$ ratio did not bring any appreciable variation in the stereochemical efficiency of the catalytic system. 